\title{
EMISSÕES DE ÁLCOOL NÃO QUEIMADO E POLUENTES LEGISLADOS DE VEÍCULO LEVE COM GASOLINA A22, A85 E EHR.
}

\author{
Katia Cristine da Costa Silva ${ }^{1}$, Luiz Carlos Daemme ${ }^{1}$, Renato Penteado ${ }^{1,2}$, Valéria de Cássia \\ Macedo ${ }^{1}$ Sérgio Machado Correa ${ }^{3}$ \\ ${ }^{1}$ Instituto de Tecnologia para o Desenvolvimento (LACTEC), ${ }^{2} \mathrm{P} \& \mathrm{~K}$ Consultoria, \\ ${ }^{3}$ Universidade do Estado do Rio de Janeiro \\ E-mails: katia.silva@lactec.org.br, luiz.carlos@lactec.org.br, renato@lactec.org.br, \\ renato@pkconsult.com.br, valeria.macedo@lactec.org.br,_sergiomc@uerj.br.
}

\section{RESUMO}

A legislação brasileira estabelece limites máximos de emissão de poluentes provenientes do escapamento de veículos leves de passageiros incluindo os hidrocarbonetos não metânicos (NMHC). Em 2004, a Instrução Normativa 54, do IBAMA, permitiu deduzir a parcela da emissão de álcool não queimado no cálculo do NMHC.

Com o aumento da participação de veículos Flex Fuel no mercado brasileiro e o respectivo aumento no uso do etanol, é possível que as emissões produzidas pelo álcool não queimado assumam maior importância nas áreas urbanas.

O objetivo do trabalho é avaliar a variação das emissões, com ênfase no álcool não queimado, com diferentes teores de etanol no combustível.

Um veículo do ciclo Otto foi testado em dinamômetro de chassis segundo a NBR 6601, no ciclo FTP 75, com gasolina A22, A85 e etanol hidratado combustível (EHR). Foram medidas as emissões legisladas de $\mathrm{HC}, \mathrm{CO}, \mathrm{NO}_{\mathrm{x}}, \mathrm{CO}_{2}$ e $\mathrm{CH}_{4}$ através de bancadas de análise de gases. Foram determinadas as emissões de formaldeído e acetaldeído por cromatografia líquida e também medida a emissão de álcool não queimado por FTIR.

Os resultados indicam um aumento nas emissões de $\mathrm{CH}_{4}$, NMHC e $\mathrm{HC}$, ao passo que ocorre uma redução de $\mathrm{CO}_{2}$. Já para $\mathrm{NO}_{\mathrm{x}}$ não houve um comportamento característico. Um aumento de CO foi observado com o aumento do uso de etanol, assim como as emissões de acetaldeído e álcool não queimado.

\section{INTRODUÇÃO}

Os gases orgânicos do tipo não metano (NMOG) são considerados os principais poluentes das emissões veiculares que contribuem para a formação de ozônio na troposfera, região que se estende desde o nível da superfície terrestre até cerca de 15 quilômetros de altitude e contém aproximadamente $85 \%$ da massa da atmosfera. Para o cálculo do valor de emissões de NMOG considera-se a soma ponderada de poluentes, sendo esses os hidrocarbonetos do tipo não metano (NMHC), aldeídos, cetonas e o álcool não queimado[1][2]. 
A formação de ozônio e outros oxidantes na troposfera é uma consequência das reações entre os óxidos de nitrogênio $\left(\mathrm{NO}_{\mathrm{x}}\right)$ e as espécies orgânicas presentes na atmosfera, dentre elas os compostos orgânicos voláteis (COV) na presença de radiação ultravioleta[3].

Segundo um estudo realizado por Alvim et al. [4], além dos COV serem importantes contribuintes na formação do $\mathrm{O}_{3}$, eles também apresentam caráter prejudicial à saúde. Compostos como o benzeno, o tolueno, e o xileno merecem atenção do ponto de vista da formação do ozônio. Os autores realizaram um estudo em uma estação de monitoramento da qualidade do ar da Companhia de Tecnologia de Saneamento Ambiental (CETESB) na região da grande São Paulo e afirmam que, depois dos hidrocarbonetos, os aldeídos são os mais abundantes gases orgânicos presentes na atmosfera. $\mathrm{O}$ resultado do referido estudo revela que, considerando os valores médios de concentração do período estudado, os dez compostos orgânicos mais abundantes encontrados, na região estudada, foram: isopentano $(6,21 \mathrm{ppbv})$, eteno (5,61 ppbv), formaldeído (5,00 ppbv), acetaldeído (4,00 ppbv), butano (3,40 ppbv), tolueno (2,86 ppbv), 1-buteno (2,57 ppbv), etano (2,5 ppbv), pentano (2,31 ppbv) e propano (2,09 ppbv).

No que diz respeito ao álcool não queimado, o metanol e o etanol são os dois alcoóis geralmente utilizados como combustíveis automotivos. O metanol é produzido principalmente a partir do gás natural, do carvão, de óleos residuais e biomassa. O etanol ou álcool etílico pode ser produzido pela fermentação do açúcar extraído a partir de biomassa (como cana-deaçúcar, milho, etc.) ou pela hidratação catalítica do etileno. Como combustível, o etanol pode ser utilizado na forma hidratada ou na forma anidra em combinação com a gasolina, resultando no combustível chamado de gasool. A utilização pelos motores veiculares do metanol, etanol e gasool (mistura entre gasolina e álcool) propicia a emissão para atmosfera do álcool não queimado e dos aldeídos [1]correspondentes (formaldeído e acetaldeído, dentre outros). O principal processo de remoção de álcoois na atmosfera é a sua reação com os radicais $\mathrm{OH}$, formando os radicais hidroxialquilas correspondentes, como apresentado nas reações 1 e 2 :

$$
\begin{aligned}
& \mathrm{CH}_{3} \mathrm{OH}+\mathrm{OH} \rightarrow \mathrm{HCHO}+\mathrm{HO}_{2} \text { Equação (1) } \\
& \mathrm{C}_{2} \mathrm{H}_{5} \mathrm{OH}+\mathrm{OH} \rightarrow \mathrm{CH}_{3} \mathrm{CHO}+\mathrm{HO}_{2} \quad \text { Equação (2) }
\end{aligned}
$$

$\mathrm{O}$ acetaldeído formado pode decompor-se fotoquimicamente ou reagir com radicais $\mathrm{OH}$ formando o radical acetil peroxi. A reação deste radical com o NO, leva à formação de formaldeído, enquanto a reação com o $\mathrm{NO}_{2}$ leva à formação de PAN (peroxi acetil nitrato), que é agente fitotóxico, irritante dos olhos. As principais vias de reação do formaldeído são a decomposição fotoquímica e a reação com radicais $\mathrm{OH}$, que na presença de oxigênio, leva à formação de $\mathrm{HO}_{2}$. A influência destes compostos na formação de ozônio acontece através da modificação da relação $\mathrm{NO} / \mathrm{NO}_{2}$ que determina as velocidades de formação e consumo de ozônio [1][3].

As emissões de álcool não queimado são emitidas principalmente na partida a frio de motores a combustão. A resolução CONAMA no 9/94 [5] estabeleceu inicialmente uma metodologia para a medição de álcool não queimado por cromatografia gasosa. Em 2008, foi publicada a norma ABNT NBR 15598 "Veículos rodoviários automotores leves - Determinação de etanol não queimado contido no gás de escapamento, por cromatografia gasosa - Método de ensaio" 
[6], que apresenta detalhes técnicos da medição do álcool não queimado em ciclo de dinamômetro.

Graner et al. [7] quantificaram e compararam as emissões de álcool (etanol) não queimado emitidas pelo gás de escapamento de veículos flex, através de medições simultâneas realizadas por FTIR e por cromatografia gasosa. Foram avaliados veículos com combustível contendo teores de etanol diferenciados, com gasolina contendo 22\% de álcool (A22); com álcool hidratado (E-100); e com a mistura de 50\% de A22 e 50\% de E-100. Os autores concluíram que os resultados das medições da emissão de etanol não queimado, obtidos por Espectrometria de Infravermelho por Transformada de Fourier e por cromatografia gasosa, são comparáveis e correlacionáveis.

Melo et al. [1] apresentaram uma revisão bibliográfica sobre as legislações de emissões dos EUA e do Brasil sobre o tema, além de estudos de metodologias de medição e cálculo no sentido de auxiliar a discussão técnica para a implantação futura de limites de emissões para o NMOG (gases orgânicos do tipo não metano) no Brasil.

Teixeira et al. [8] mediram ozônio e seus precursores em Porto Alegre. Mediram os óxidos de nitrogênio e monóxido de carbono, associados a variáveis meteorológicas. Os resultados mostraram que a concentração de ozônio mantém-se inalterada durante os dias de semana. Níveis de $\mathrm{NO}_{\mathrm{x}}$ decrescem em finais de semana, em função da redução do tráfego de automóveis.

Arbilla e Oliveira [3] estudaram uma forma de otimização de um mecanismo fotoquímico para a simulação da atmosfera urbana brasileira. Teceram considerações a respeito dos processos para formação do ozônio e outros oxidantes na troposfera e aplicaram um modelo, comparando com resultados reais, na cidade do Rio de Janeiro. O modelo ofereceu uma resposta satisfatória para as espécies de maior interesse nos estudos de qualidade do ar (ozônio, PAN, $\mathrm{NO}$ e $\mathrm{NO}_{2}$ ).

Correa et al. [9] monitoraram a formação de formaldeído e acetaldeído na região central da cidade do Rio de Janeiro. Concluíram que o uso do etanol, a partir dos anos 70, levou a um aumento da presença de acetaldeído e uma maior relação acetaldeído/formaldeído, se comparada com outros países. Citam que, desde 2000, o uso de gás natural está associado a um aumento dos níveis de formaldeído, com posterior redução com a aplicação de kits mais evoluídos de conversão. O artigo conclui que o formaldeído é o principal precursor de ozônio no Rio de janeiro, e o acetaldeído ocupa o quarto lugar.

\section{OBJETIVO}

$\mathrm{O}$ objetivo do trabalho foi medir as emissões de $\mathrm{HC}, \mathrm{CO}, \mathrm{NOx}, \mathrm{CO}_{2}, \mathrm{CH}_{4}$, formaldeído, acetaldeído e álcool não queimado em um veículo do ciclo Otto, abastecido com combustíveis A22, A85 e EHR. O álcool não queimado foi medido pela técnica de FTIR.

\section{METODOLOGIA}

Os testes foram realizados em um dinamômetro de chassis de 48" de acordo com o ciclo de condução FTP 75 e a norma brasileira NBR6601[10]. Emissões regulamentadas (CO, 
$\mathrm{HC}$ e $\mathrm{NO}_{\mathrm{x}}$ ) foram medidas com bancadas Horiba série 7000. Os aldeídos foram determinados pela técnica de Cromatografia Líquida de Alta Desempenho (HPLC) de acordo com a norma brasileira NBR12026 [11]. O álcool não queimado foi determinado com auxílio da técnica de espectroscopia na região do infravermelho com transformada de Fourier (FTIR). A taxa de fluxo da amostra para o analisador FTIR foi de 6 litros por minuto, utilizando-se uma linha de amostra aquecida. As medições foram realizadas nos gases de escapamento brutos (não diluído).

Pelo menos três ensaios foram realizados para cada tipo de combustível. Para análise dos dados, foi utilizada a análise de variância (ANOVA). O diagrama de procedimento de teste pode ser observado na FIGURA 1.

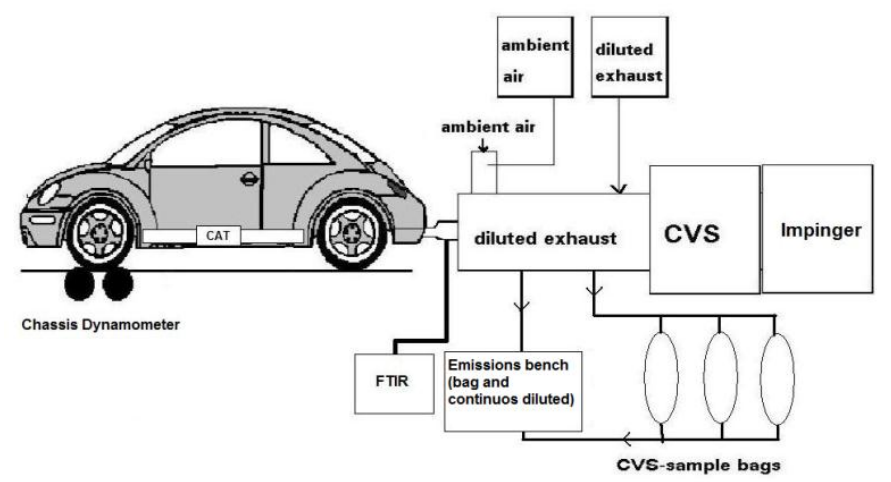

FIGURA 1 - Diagrama dos ensaios

\section{Especificação do veículo}

O veículo utilizado foi um automóvel leve de passageiros, do ciclo Otto, com as seguintes características: potência de $115 \mathrm{CV}$; torque: $157 \mathrm{Nm}$ a $3750 \mathrm{rpm}, 1.6$ litros, 16 válvulas; massa de inércia de $1474 \mathrm{~kg}$; modelo do ano 2009; $19.000 \mathrm{~km}$ no início do programa de testes, sistema de injeção eletrônica EFI; Flex Fuel; conversor catalítico de três vias, acoplado em circuito fechado.

\section{Especificação do combustível}

Os combustíveis utilizados nos ensaios foram Gasool A22 com (78\% em volume de gasolina do tipo A e $22 \%$ de etanol anidro combustível de referência - EAR); A85 (85\% em volume de etanol anidro e $15 \%$ em volume de gasolina pura) e EHR(etanol hidratado combustível de referência ). Os combustíveis utilizados são específicos para ensaios de homologação e atendem a norma ABNT NBR 8689/2012, resoluções ANP 06/2005 e ANP 23/2010 para ensaios de homologação.

\section{RESULTADOS E DISCUSSÕES}

Os resultados dos testes relativos a $\mathrm{HC}, \mathrm{CH}_{4}, \mathrm{NMHC}$ são apresentados na FIGURA 2. Observou-se que as emissões aumentam com o teor de etanol na mistura de combustível. Salienta-se que os valores de NMHC apresentados não contemplam o desconto de álcool não queimado. As barras de erros apresentadas correspondem a um desvio padrão para cada poluente. 


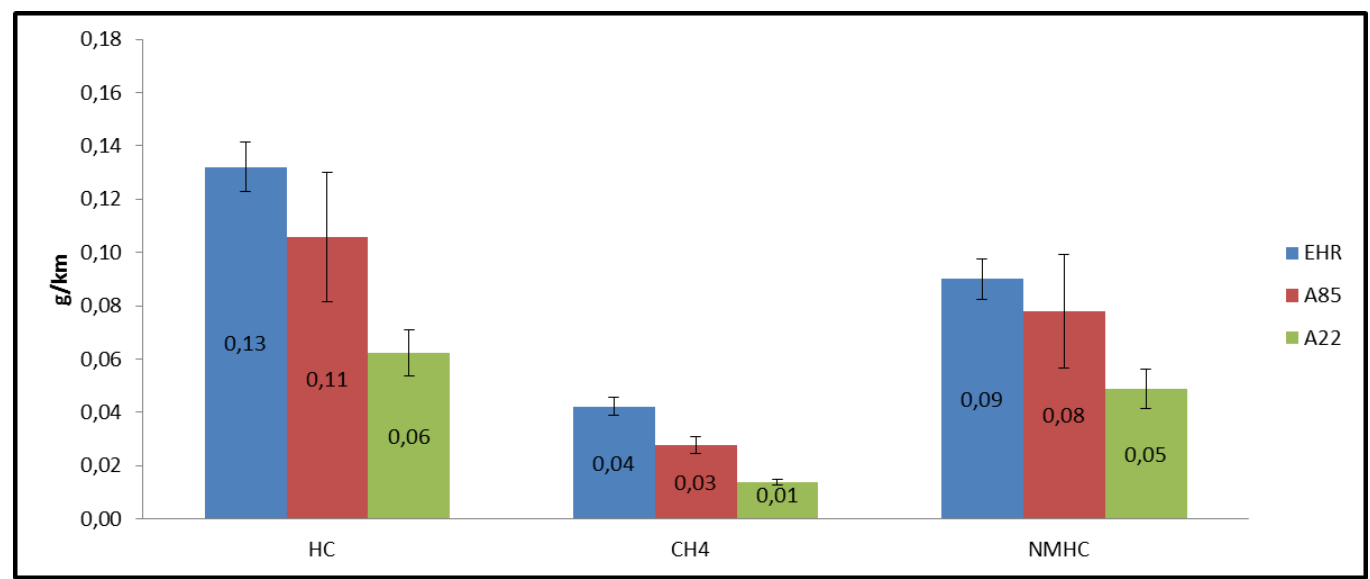

FIGURA 2 - Emissões $\mathrm{HC}, \mathrm{CH}_{4}$ e NMHC

A FIGURA 3 apresenta as emissões de CO com a variação do teor de álcool no combustível.

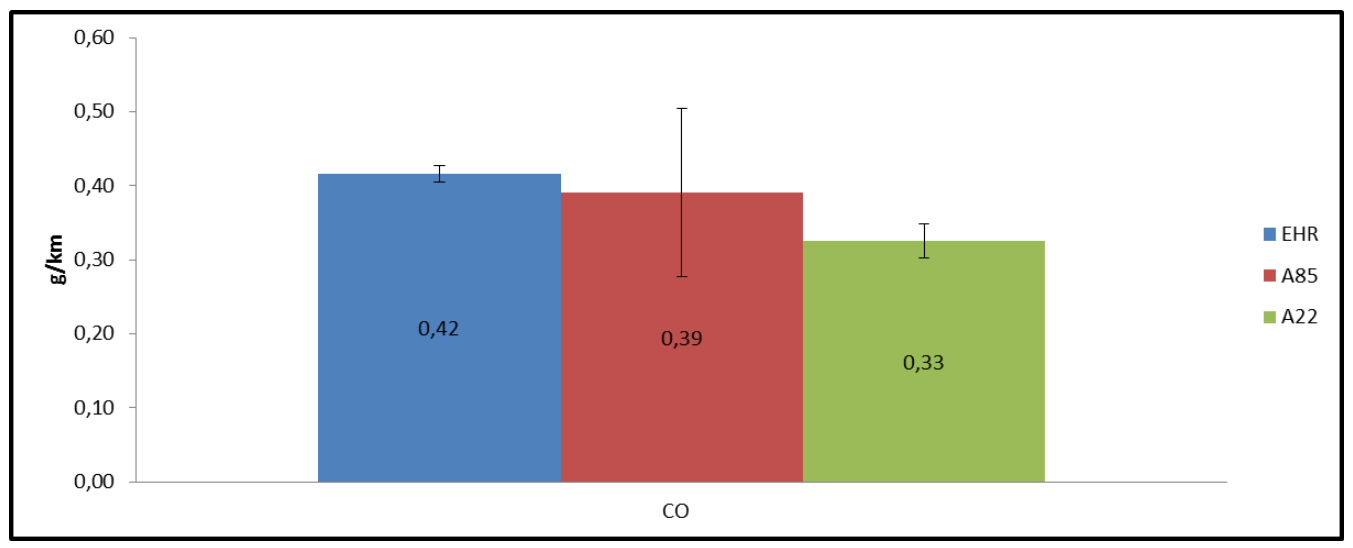

FIGURA 3 - Emissões de CO

Karavalakisa et al. [12] publicaram que as emissões de HC, NHMC e CO geralmente diminuem com redução do etanol, exceto na mistura de E85. Em contrapartida, resultados apresentados em um estudo do NREL [13] mostram uma redução das emissões de CO com o aumento do teor de etanol na mistura do combustível. Essas diferenças podem ser devido à aplicação de tecnologias diferentes no veículo e aos dispositivos de pós tratamento dos gases de escape.

A FIGURA 4 apresenta os resultados de NOx para os três tipos de combustível ensaiados. 


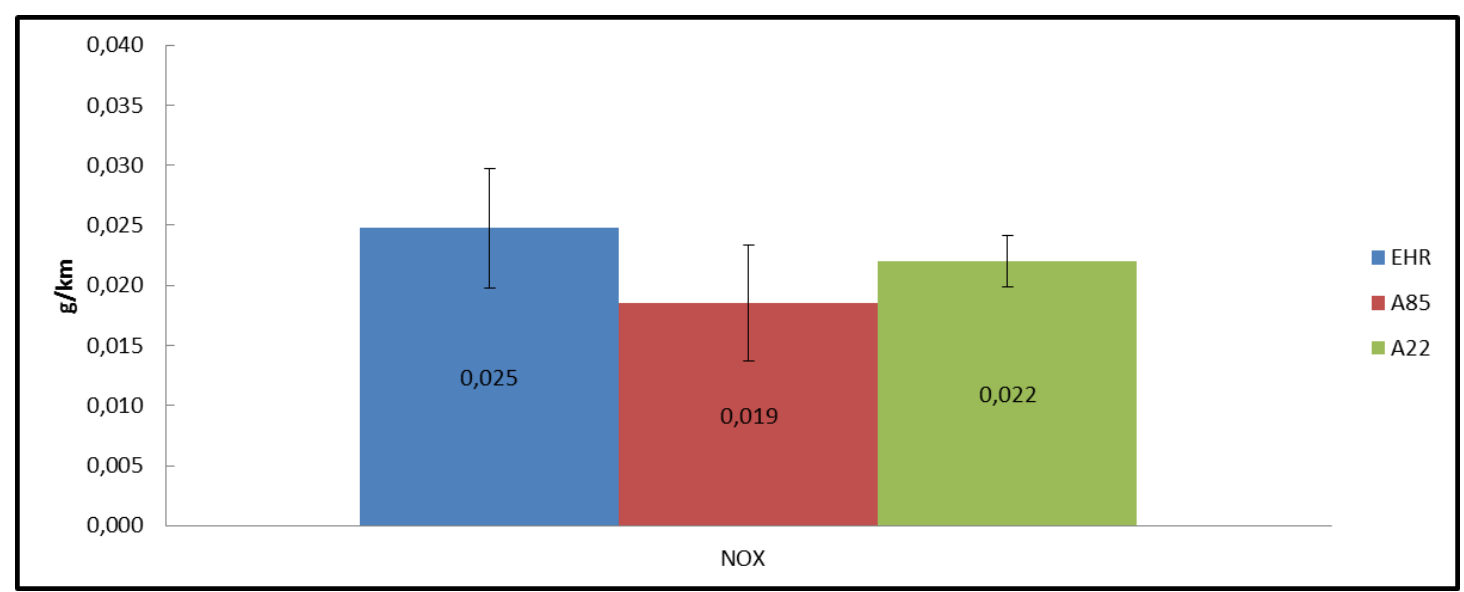

FIGURA 4 - Emissões de NOx

As emissões de NOx não se alteraram significativamente com o combustível. Resultados semelhantes foram observados pelo NREL[13]

A FIGURA 5 apresenta a tendência das emissões de $\mathrm{CO}_{2}$. Uma maior participação da gasolina na mistura leva a um aumento da emissão desse composto.

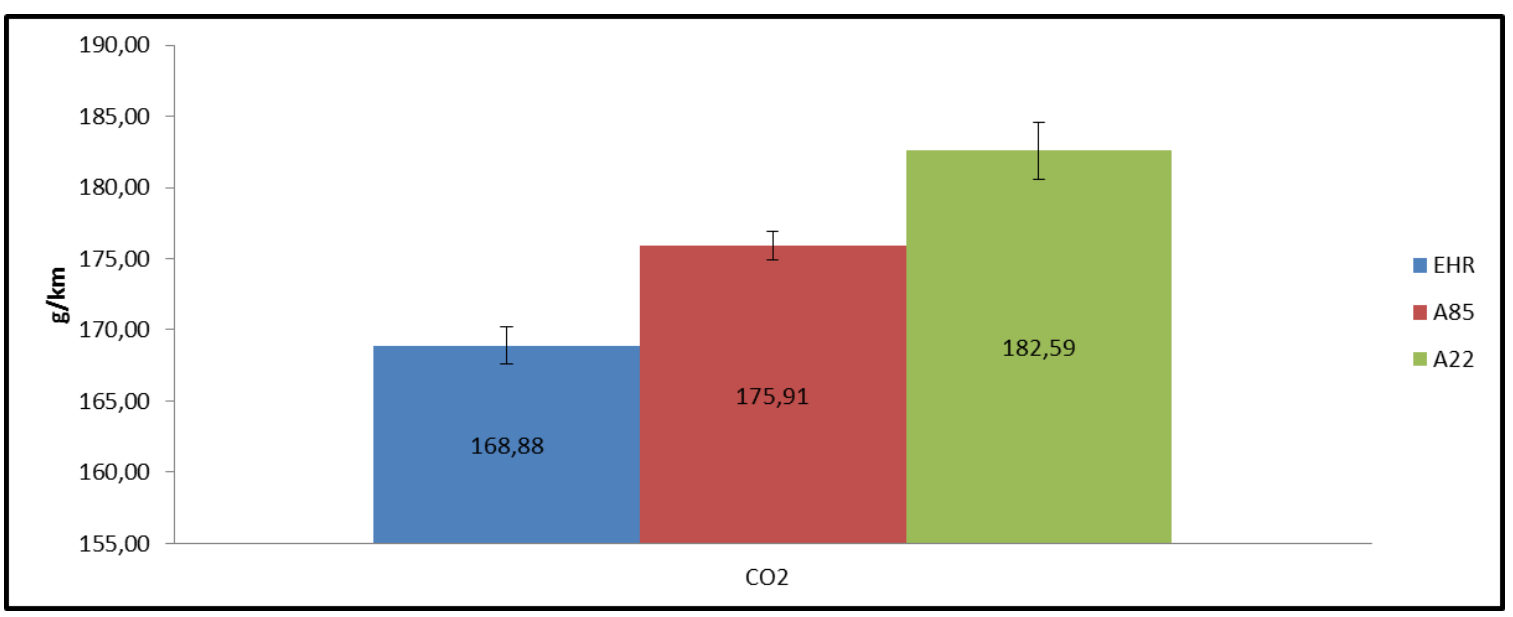

FIGURA 5 - Emissões de $\mathrm{CO}_{2}$

A autonomia do veículo é apresentada na FIGURA 6, calculada conforme a NBR 7024/2010. Os veículos mostraram um aumento no consumo de combustível numa tendência linear com o aumento do conteúdo de etanol. Este resultado era esperado porque o etanol tem menor poder calorífico que a gasolina. Resultados semelhantes foram obtidos por Knoll et al. [14] 


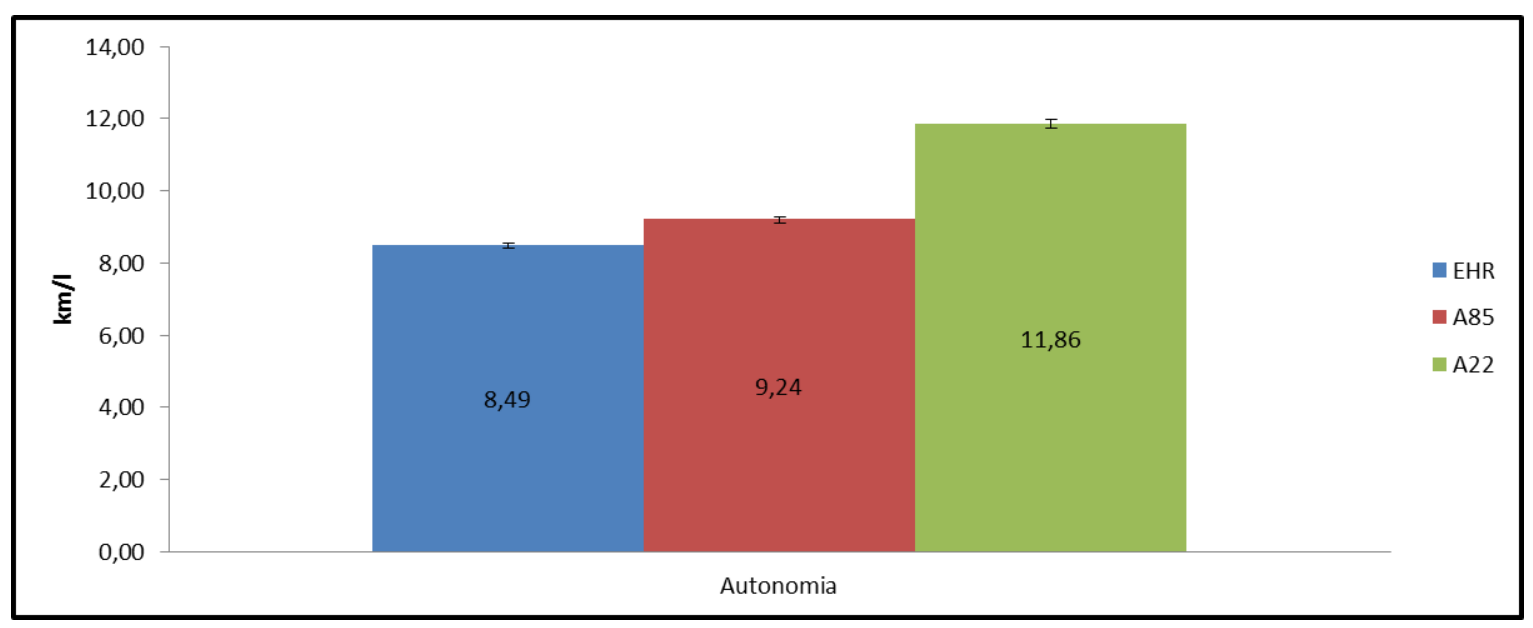

FIGURA 6 - Consumo de Combustível

A FIGURA 7 apresenta os resultados de aldeídos, medidos por cromatografia líquida.

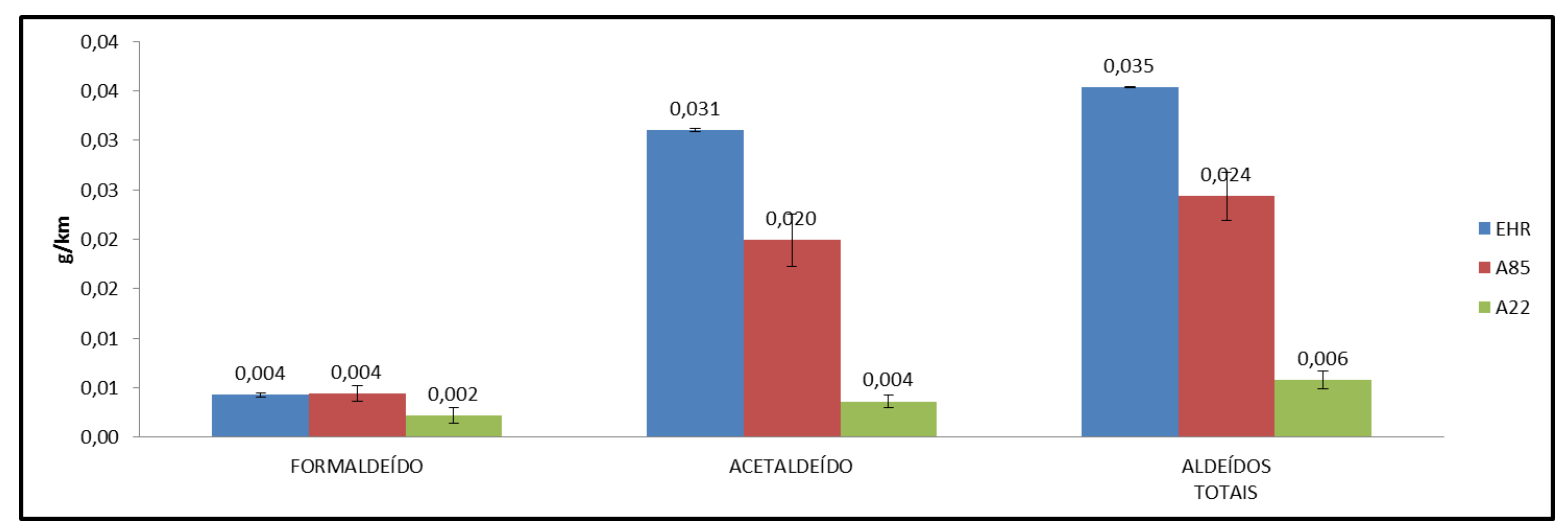

FIGURA 7 - Emissões de Aldeídos (g/km)

As medições de álcool não queimado (ANQ) foram feitas por FTIR, nos três combustíveis.

A FIGURA 8 mostra a média de três testes, em partes por milhão (ppm), obtidos por FTIR. Observa-se uma expressiva variação das emissões de ANQ em função do teor de álcool no combustível.

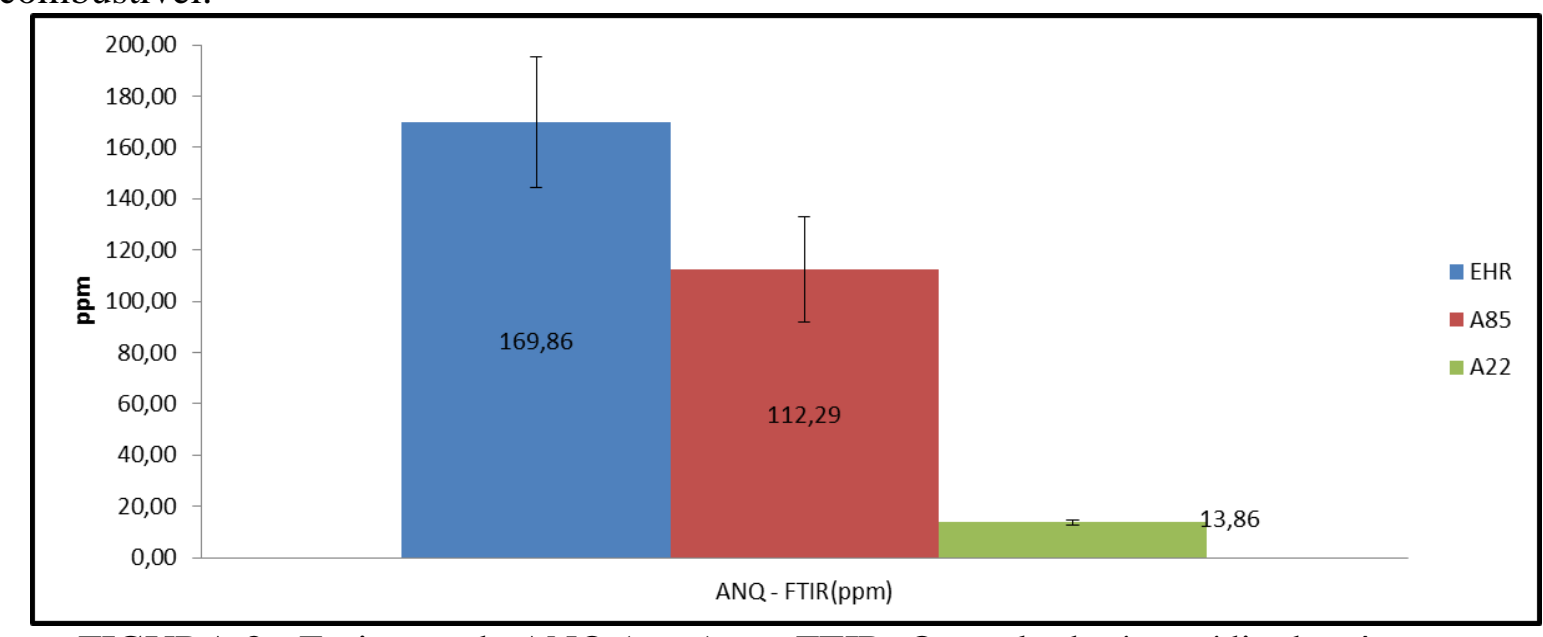

FIGURA 8 - Emissões de ANQ (ppm) por FTIR. O resultado é a média de três testes realizados. 
A FIGURA 9 apresenta a medição de álcool não queimado, segundo a segundo, por FTIR. Nela pode ser observado que no início do ciclo, em sua fase fria, os valores são mais expressivos, se comparados com o restante do ciclo, onde se aproximam e tendem a uma estabilização.

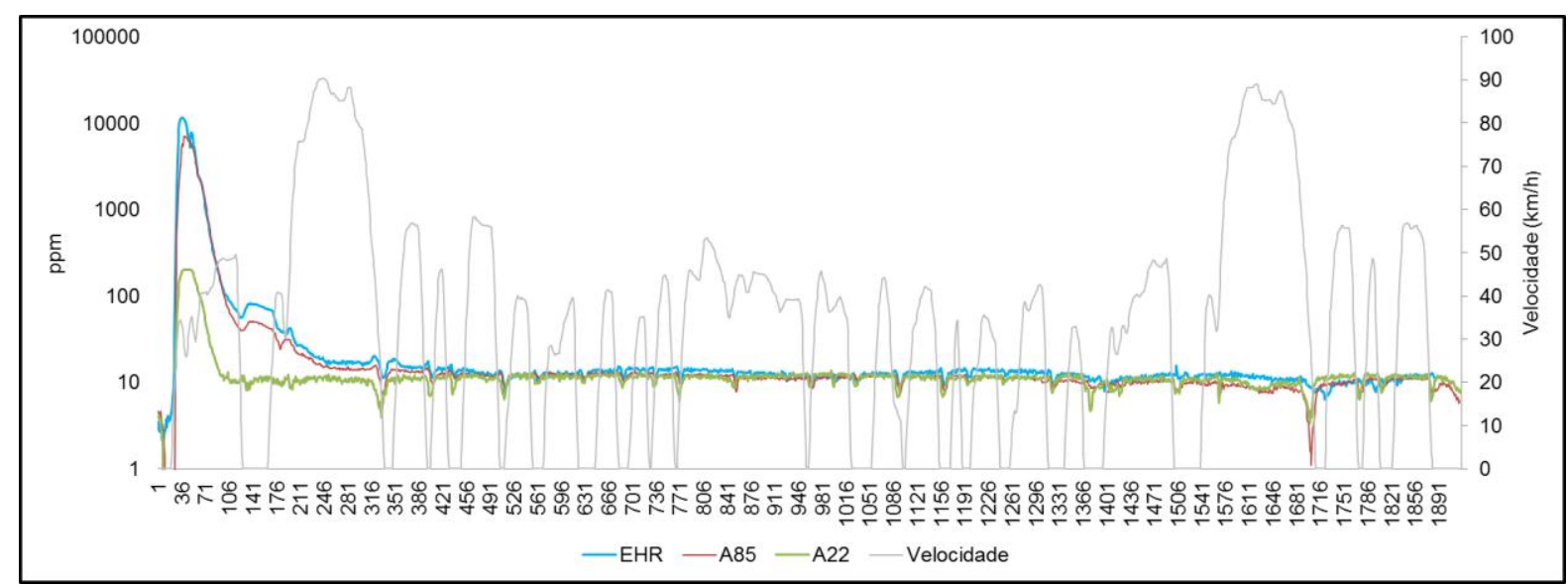

FIGURA 9 - Emissões de ANQ (ppm). Gráfico segundo a segundo da medição de emissões por FTIR em um teste realizado no ciclo FTP-75, com EHR. 
A TABELA 1 apresenta o resultado da análise estatística para as emissões. Como exemplo de interpretação da tabela, tome-se uma comparação entre os combustíveis EHR e A85, na emissão de THC. Da tabela extraí-se que as emissões de THC são diferentes e maiores para EHR se comparadas com A85.

TABELA 1 - Análise estatística das emissões regulamentadas Resultado da análise estatitística para as emissões de THC e NOX

\begin{tabular}{cccc|ccc}
\hline Poluentes & \multicolumn{3}{c|}{ THC } & \multicolumn{3}{c}{ Nox } \\
\hline \multirow{2}{*}{ Combustíveis } & \multicolumn{9}{c}{ Comparação } \\
\cline { 2 - 8 } & EHR & A85 & A22 & EHR & A85 & A22 \\
\hline EHR & & $\neq>$ & $\neq>$ & & $\neq>$ & $=$ \\
\hline A85 & & $\neq>$ & & \\
\hline A22 & & & & \\
\hline
\end{tabular}

Resultado da análise estatitística para as emissões de CO e NMHC

\begin{tabular}{cccc|ccc}
\hline Poluentes & \multicolumn{9}{c|}{ CO } & \multicolumn{3}{c}{ NMHC } \\
\cline { 2 - 7 } Combustíveis & \multicolumn{9}{c}{ Comparação } \\
\cline { 2 - 7 } & EHR & A85 & A22 & EHR & A85 & A22 \\
\hline EHR & & $=$ & $\neq>$ & & $\neq>$ & $\neq>$ \\
\hline A85 & & $\neq>$ & & \\
\hline A22 & & & & \\
\hline
\end{tabular}

Resultado da análise estatitística para as emissões de $\mathrm{CO}_{2}$ e Autonomia

\begin{tabular}{|c|c|c|c|c|c|c|}
\hline \multirow{3}{*}{$\begin{array}{c}\text { Poluentes } \\
\text { Combustíveis }\end{array}$} & \multicolumn{3}{|c|}{$\mathrm{CO}_{2}$} & \multicolumn{3}{|c|}{ Autonomia } \\
\hline & \multicolumn{6}{|c|}{ Comparação } \\
\hline & EHR & A85 & A22 & EHR & A85 & A22 \\
\hline EHR & & $\neq>$ & $\neq>$ & & $=$ & $\neq>$ \\
\hline A85 & & & $\neq>$ & & & $\neq>$ \\
\hline A22 & & & & & & \\
\hline
\end{tabular}

Resultado da análise estatitística para as emissões de ANQ - FTIR

\begin{tabular}{cccc}
\hline Poluentes & \multicolumn{3}{c}{ ANQ } \\
\cline { 2 - 4 } Combustíveis & EHR & A85 & A22 \\
\cline { 2 - 4 } & & $\neq>$ & $\neq>$ \\
\hline EHR & & & $\neq>$ \\
\hline A85 & & \\
\hline A22 & & \\
\hline
\end{tabular}

\section{CONCLUSÕES}


Os resultados permitem concluir que as emissões de $\mathrm{HC}, \mathrm{CH}_{4}$ e $\mathrm{NMHC}$, aumentam diretamente com o teor de álcool na mistura do combustível, sem considerar a emissão de álcool não queimado.

O consumo de combustível aumenta diretamente com o teor de álcool. Este fato pode ser explicado pela menor poder calorífico do álcool, se comparado com o da gasolina.

A mesma tendência observou-se para o álcool não queimado. Como a geração do álcool não queimado está diretamente relacionada a uma queima incompleta na câmara de combustão, quanto maior o teor de álcool no combustível, maior a sua emissão.

Verificou-se uma geração expressiva de álcool não queimado na primeira fase do ciclo FTP 75 , se comparado com as demais. Este fato é explicado pelo ensaio iniciar com o conjunto (motor e catalisador) entre 20 e $30^{\circ} \mathrm{C}$. O conversor catalítico de três vias tem operação otimizada em temperaturas elevadas, ou seja, nas fases 2 e 3 , o que explica sua baixa eficiência na fase 1 .

De uma forma geral pode-se concluir que o uso do etanol, que é um combustível renovável, é benéfico em termos de emissões para a atmosfera, com exceção a geração de álcool não queimado. Entretanto, a toxidez do álcool não queimado é baixa, assim como sua reatividade na atmosfera. O principal ponto negativo é a formação de acetaldeído, mais significativa com a utilização de etanol, que pode gerar ozônio na troposfera além de ser um composto potencialmente cancerígeno. Esse é um problema que deve ser, melhor estudado, em especial, na otimização dos sistemas de injeção de combustível e na eficiência dos catalisadores na fase fria de operação.

\section{AGRADECIMENTOS}

Os autores agradecem ao Ministério da Ciência e Tecnologia e ao CNPq (Conselho Nacional de Desenvolvimento Científico e Tecnológico) pelo incentivo recebido com a aplicação da Lei 8010/90. Agradecem também à equipe do Laboratório de Emissões Veiculares do Lactec, onde foram realizados os testes de emissões, e ao PRODETEC (Programa de Pós-graduação em Desenvolvimento de Tecnologia).

\section{REFERÊNCIAS BIBLIOGRÁFICAS}

[1] MELO, T. C. C.; COLNAGO, K.; LOUREIRO, L.N. Implantação dos gases orgânicos do tipo não metano (NMOG) no Brasil. SIMEA. São Paulo, 2009.

[2] ORLANDO, J.P. Estudo dos precursores de ozônio da cidade de São Paulo através de simulação computacional. Dissertação (Mestrado em Ciências na área de Tecnologia Nuclear - Materiais) - Programa de pós-graduação do IPEN, Universidade de São Paulo. São Paulo, 2008. 
[3] ARBILLA, G.; OLIVEIRA, K.M.P.G. Otimização de um mecanismo fotoquímico para a simulação da atmosfera urbana brasileira. QUÍMICA NOVA, 22(6), p. 790800. 1999.

[4] ALVIM, D.S.; GATTI,V.N; SANTOS, M.H.; YAMAZAKI. A. Estudos dos compostos orgânicos voláteis precursores de ozônio na cidade de São Paulo. Eng Sanit Ambient, v.16 n.2, abr/jun 2011, p. 189-196. 2011.

[5] INSTRUÇÃO NORMATIVA no 09, 1994, IBAMA.

[6] ASSOCIAÇÃO BRASILEIRA DE NORMAS TÉCNICAS. Veículos rodoviários automotores leves - Determinação de etanol não queimado contido no gás de escapamento por Cromatografia Gasosa - Método de Ensaio - ABNT NBR 15598, 2008 .

[7] GRANER, L.; SERTEK, C.A.O. ; JOSEPH, H. Estudo comparativo das medições das emissões de álcool não queimado emitidas por veículos flex analisadas simultaneamente por FTIR e por CG. SAE, SP, 2005.

[8] TEIXEIRA, E.C.; SANTANA, E.R.; WIEGAND, F.; FACHEL, J. Measurement of surface ozone and its precursors in an urban area in South Brazil. Atmospheric Environment 43 (2009), 2213-2220.

[9] CORREA, S.M.; ARBILLA, G.; MARTINS, E.M.; QUITÉRIO, S.L.; GUIMARÃES, C.S.; GATTI, L.V. Five years of formaldehyde and acetaldehyde monitoring in the Rio de Janeiro downtown area - Brazil. Atmospheric Environment 44 (2010) 23022308 .

[10] ABNT. NBR 6601: Determinação de hidrocarbonetos, monóxido de carbono, óxidos de nitrogênio, dióxido de carbono e material particulado no gás de escapamento, 2012.

[11] ABNT - ASSOCIAÇÃO BRASILEIRA DE NORMAS TÉCNICAS. NBR 12026 Veículos rodoviários automotores leves - Determinação da emissão de aldeídos e cetonas contidas no gás de escapamento, por cromatografia líquida - Método DNPH. Rio de Janeiro, 2009

[12] KARAVALAKISA, G., DURBINA, T.D., SHRIVASTAVA, M., ZHENGA, Z., VILLELAA, M., JUNGA. J. "Impacts of ethanol fuel level on emissions of regulated and unregulated pollutants from a fleet of gasoline light-duty vehicles. FUEL, v93, March 2012, 549-558.

[13] DOE - US Department of Energy. Alternative Fuels Data Center. "Ethanol vehicle emissions". Retrieved from http://www.afdc.energy.gov/vehicles/flexible_fuel_emissions.html,(accessed Oct 02, 2012) 
[14] KNOLL, K., WEST W, B., CLARK, W., GRAVES, R., ORBAN, J., PRZESMITZKI, S., THEISS, T. "Effects of intermediate ethanol blends on legacy vehicles and small non-road engines, report 1 - updated". NREL/TP-540-43543, 2008.

[15] ENVIRONMENTAL PROTECTION UK. "Ozone pollution". Retrieved from http://www.environmental-protection.org.uk/air-quality-and-climate/air-quality/ozonepollution/, (accessed Oct 02, 2012). 